\title{
Maternal Complication of Pregnancy
}

National Cancer Institute

\section{Source}

National Cancer Institute. Maternal Complication of Pregnancy. NCI Thesaurus. Code C35594.

The development of a problematic medical situation that occurs during pregnancy. 